\title{
Natural Product Inhibition and Enzyme Kinetics Related to Phylogenetic Characterization for Bacterial Peptidyl-tRNA Hydrolase 1
}

\author{
D. Scott Strange ${ }^{1}$, Steven S. Gaffin ${ }^{2}$, W. Blake Holloway ${ }^{1}$, Meredyth D. Kinsella ${ }^{2}{ }^{\circledR}$, Jacob N. Wisotsky ${ }^{2}$, \\ Hana McFeeters ${ }^{1}$ and Robert L. McFeeters ${ }^{1, *}$ \\ 1 Department of Chemistry, University of Alabama in Huntsville, Huntsville, AL 35899, USA; \\ djs0018@uah.edu (D.S.S.); wbholloway2@gmail.com (W.B.H.); hk0003@uah.edu (H.M.) \\ 2 Department of Biology, University of Alabama in Huntsville, Huntsville, AL 35899, USA; \\ steven.s.gaffin@gmail.com (S.S.G.); mdk0012@uah.edu (M.D.K.); jacobwisotsky@gmail.com (J.N.W.) \\ * Correspondence: robert.mcfeeters@uah.edu; Tel.: +1-256-824-6023
}

\section{check for} updates

Citation: Strange, D.S.; Gaffin, S.S.; Holloway, W.B.; Kinsella, M.D.; Wisotsky, J.N.; McFeeters, H.; McFeeters, R.L. Natural Product Inhibition and Enzyme Kinetics Related to Phylogenetic Characterization for Bacterial Peptidyl-tRNA Hydrolase 1. Molecules 2021, 26, 2281. https:// doi.org/10.3390/molecules26082281

Academic Editor: Jean-Marc Sabatier

Received: 21 February 2021

Accepted: 12 April 2021

Published: 15 April 2021

Publisher's Note: MDPI stays neutral with regard to jurisdictional claims in published maps and institutional affiliations.

Copyright: (c) 2021 by the authors. Licensee MDPI, Basel, Switzerland. This article is an open access article distributed under the terms and conditions of the Creative Commons Attribution (CC BY) license (https:// creativecommons.org/licenses/by/ $4.0 /)$.

\begin{abstract}
With the relentless development of drug resistance and re-emergence of many pathogenic bacteria, the need for new antibiotics and new antibiotic targets is urgent and growing. Bacterial peptidyl-tRNA hydrolase, Pth1, is emerging as a promising new target for antibiotic development. From the conserved core and high degree of structural similarity, broad-spectrum inhibition is postulated. However, Pth1 small-molecule inhibition is still in the earliest stages. Focusing on pathogenic bacteria, herein we report the phylogenetic classification of Pth1 and natural product inhibition spanning phylogenetic space. While broad-spectrum inhibition is found, narrow-spectrum and even potentially clade-specific inhibition is more frequently observed. Additionally reported are enzyme kinetics and general in vitro Pth1 solubility that follow phylogenetic boundaries along with identification of key residues in the gate loop region that appear to govern both. The studies presented here demonstrate the sizeable potential for small-molecule inhibition of Pth1, improve understanding of Pth enzymes, and advance Pth1 as a much-needed novel antibiotic target.
\end{abstract}

Keywords: peptidyl-tRNA hydrolase; novel antibiotic target; protein biosynthesis; phylogenetic analysis; natural product inhibition; broad- and narrow-spectrum inhibition

\section{Introduction}

With the relentless development of drug resistance and re-emergence of many pathogenic bacteria, new antibiotics and new antibiotic targets are in critical need. Bacterial peptidyltRNA hydrolase (Pth1) is emerging as a promising new avenue for antibiotic development. Pth1 performs the necessary function of recycling peptidyl-tRNA naturally generated from protein biosynthesis [1-3] or the expression of minigenes and short ORFs [4-6]. Accumulation of peptidyl-tRNA is toxic to cells, obstructing protein translation and rapidly leading to cell death from tRNA starvation [7]. Whereas Pth1 is essential in a vast majority of pathogenic bacteria [8,9], eukaryotes have redundant peptidyl-tRNA hydrolases that are structurally and mechanistically unrelated, yet complement Pth1 function $[9,10]$. Thus, inhibiting the essential function of Pth1 in bacteria provides a new avenue for antibiotic development. Interrupting protein translation, but not affecting the ribosome, Pth1 inhibition has many advantages in regards to antibiotic development. Inhibition of protein biosynthesis is a proven antibiotic strategy employed by currently used therapeutics, such as aminoglycosides, tetracyclines, and macrolides which target the ribosome. However, being a new target, Pth1 inhibitors will be effective against drug-resistant bacterial strains. With the redundancy of Pth enzymes in eukaryotes and knock-out of Pth1 in yeast having no effect on viability [10], it is expected that Pth1 inhibitors would demonstrate bactericidal activity without significant eukaryotic cytotoxicity. Similarly, with an estimated order of 
magnitude fewer Pth1 enzymes compared to ribosomes in a typical bacterial cell [4], there is a considerable stoichiometric advantage to targeting Pth1 over the ribosome. Overall, Pth1 holds great promise as a much needed avenue for new antibiotic development.

An additional advantage to antibiotic development targeting Pth1 is the existing large structural knowledgebase. From the multitude of high-resolution structures reported to date, all have related backbone folds that maintain the recognizable core of $\alpha / \beta$-hydrolases. Three key catalytic residues including Asn10, Asp93, and essential His20 (numbering from E. coli Pth1, PDBID 2PTH) are found in the active site cleft, see Figure 1 [11]. The active site cleft in Pth1 enzymes is formed by a base loop, a gate loop, and a lid loop. The base loop forms one side of the cleft while the lid and gate loop form the opposite side of the cleft. Dynamic mobility in the microsecond-millisecond range has been reported for the region surrounding the active site in Pth1 from Mycobacterium tuberculosis and Vibrio cholerae [12,13]. The helix-4 loop serving as a lid over the active site was shown to be the most dynamic, while the gate loop region and helix-3 were more rigid. The binding of partial or minisubstrates along with computational docking provided preliminary insight into substrate recognition [14-18]. A crystal structure of $E$. coli Pth1 in complex with the non-peptide attached TYC loop of tRNA ${ }^{\text {Ala }}$ [16] and small-angle neutron scattering characterization of a catalytically inactive E. coli Pth1 mutant bound to heterogeneous peptidyl-tRNAs [17] provided some understanding of selectivity and specificity for peptidyl-tRNAs. Furthermore, past results using tRNA mimics missing the TYC arm resulted in E. coli Pth1 having a 10-fold loss in catalytic efficiency, but the enzyme retained the ability to hydrolyze peptidyl-tRNA [14]. From early enzyme kinetic studies, the length of the substrate peptide moiety, increasing up to four amino acids, correlates with higher affinity $\mathrm{K}_{\mathrm{m}}$ values [19]. While structure/function studies continue to improve understanding of Pth1 enzymes, no high-resolution structure of a Pth1:peptidyl-tRNA complex has been reported to date.

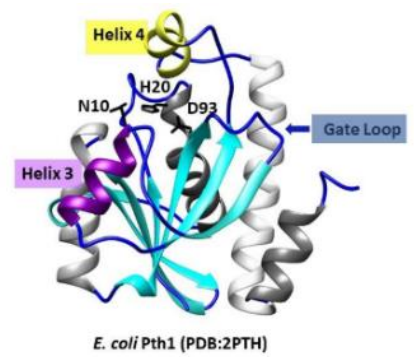

Figure 1. The crystal structure of E. coli Pth1 (PDBID: 2PTH). Labeled are the catalytic residues N10, $\mathrm{H} 20$, and D93, helix-3 in purple, helix-4 in yellow, and the gate loop. On the right is the amino acid sequence alignment.

Complementing structural studies but still in its infancy, small-molecule inhibition of Pth1 is emerging $[20,21]$. Particularly enabling are advances in functional assays $[18,22]$ and fluorescent substrates for potential high throughput screening [23]. Even with modest throughput methods, a diversity of natural products and synthetic compounds have been shown to inhibit Pth1 $[17,24,25]$. Thus it appears there are enormous reservoirs of small molecules that may serve as rich sources of lead compounds against this novel antibiotic target. Since a significant proportion of new drugs against infectious disease originate from natural sources [26,27], tremendous potential exists for small-molecule Pth1 inhibition.

Herein we report the phylogenetic classification of Pth1 from pathogenic bacteria and quantitate inhibition of a common panel of natural product extracts against Pth1s spanning phylogenetic space. We also report enzyme kinetics and in vitro protein properties that correlate to phylogenetic clades. Phylogenetic characterization shows that Pth1 enzymes occupy three distinct phylogenetic clades which are related to Gram specificity. Natural product inhibition demonstrates the possibility for broad as well as narrow-spectrum, and, potentially, clade-specific inhibition. Kinetic analysis further highlights the differences between phylogenetic clades, with common $\mathrm{V}_{\max }$ but differing $\mathrm{K}_{\mathrm{m}}$ values. Utilizing site- 
directed mutagenesis, residue differences in the gate loop were shown to affect kinetics and general properties of Pth1s from different clades. This is the first large-scale phylogenetic classification of bacterial Pth1 and the first report of observed narrow-spectrum Pth1 inhibition. This study demonstrates how including homologs spanning phylogenetic space adds important dimensions to antibiotic development and that quite different smallmolecule inhibition can be observed for highly conserved enzymes. Overall, the results presented here are important steps for continued antibiotic development targeting Pth1.

\section{Results}

\subsection{Phylogenetic Tree}

While the phylogenetic analysis focused on pathogenic bacteria, Pth1 from three relevant non-pathogenic bacterial species were also included. Specifically, Pth1 from Bacillus cereus, Bacillus subtilis, and Mycobacterium smegmatis were included since they are commonly used as substitute models for related, highly pathogenic species. Simple phylogenetic characterization of Pth1 revealed three major clades, see Figure 2A. Clade composition correlated with Gram specificity. While Clade 1 is strictly populated by Pth 1 from Gramnegative bacteria (like E. coli Pth1), Pth1 from Gram-positive bacterial species populate Clade 3. Clade 2 is intermediate, composed of Pth1 from both Gram-positive and Gramnegative bacteria along with several Gram-indistinct members. The theme of Clade 1 being distinct from Clade 3, with Clade 2 being intermediary, holds true for several other Pth1 properties, presented below.

The initial phylogenetic tree was subject to a bootstrap analysis that revealed that the clade separation may not be very robust. Therefore, a more sophisticated phylogenetic approach $[28,29]$ was used that produced a tree, in which a majority of the guide tree associations are retained and the bootstrap values better supported the branch separation. However, unlike in the initial phylogenetic tree, only two main clades exist, Figure 2B. The new Clade 1 contains predominantly Pth 1 from Gram-positive species and its composition is the same as in the initial guide tree with H. pylori and C. jejuni Pth1 no longer part of the clade. Since these two species are Gram-negative, it appears that the inclusion of their Pth1 enzymes in the large second clade fits with the Gram-positive/Gram-negative separation. The larger clade, Clade 2, is composed of Pth1 from primarily Gram-negative bacterial species. The division between Clade 2 and 3 from the initial guide tree is not as pronounced, however clear separation between the two groups is still retained. The observation that members of Clade 1 are distinct from Clade 3 (using the simple phylogenetics notation) holds, with members from Clade 2 still being intermediate.

In regards to the solubility of Pth1, it was generally found that the Clade 1 homologs expressed well and were highly soluble under typical conditions. Clade 3 homologs were not very soluble and expression conditions needed to be optimized for the production of significant amounts of soluble recombinant protein. Interestingly, the Clade 2 homolog $M$. tuberculosis Pth1, demonstrated intermediate solubility, between those generally found for Clade 1 and Clade 3 homologs.

Upon inspection of the aligned Pth1 amino acid sequences, one of the most notable differences between the clades was in the gate loop region, see Figure 3. In order to determine the effect of these amino acid differences in the gate loop, site-directed mutagenesis was utilized. S. aureus Pth1 (Gram-positive, Clade 3) gate loop region residues were individually mutated to those of $P$. aeruginosa Pth1 (Gram-negative, Clade 1). The following three mutants were produced: E99P, Q100P, and Q102V. Glycine 101 is conserved, so was not altered. Of note, G101D in E. coli Pth1 imparts temperature sensitivity [30]. Unlike wild-type S. aureus Pth1 that is expressed relatively insoluble under typical conditions, $P$. aeruginosa Pth1 is quite soluble. Thus we characterized solubility for all three gate loop mutations. E99P showed a trend towards increased solubility ( $p$-value of 0.06 ) when grown and induced for both typical and S. aureus optimized growth conditions, see Figure 4. This is evident from the increased intensity of Pth1 in the soluble fraction compared to the pellet. The Q100P mutation resulted in little to no soluble protein. It is speculated that 
disruption of the Q100-D154 salt bridge unique to S. aureus Pth1 is the cause. Q102V did not appear to have any effect on solubility and only the atypical wild-type S. aureus Pth1 growth conditions produced soluble protein.

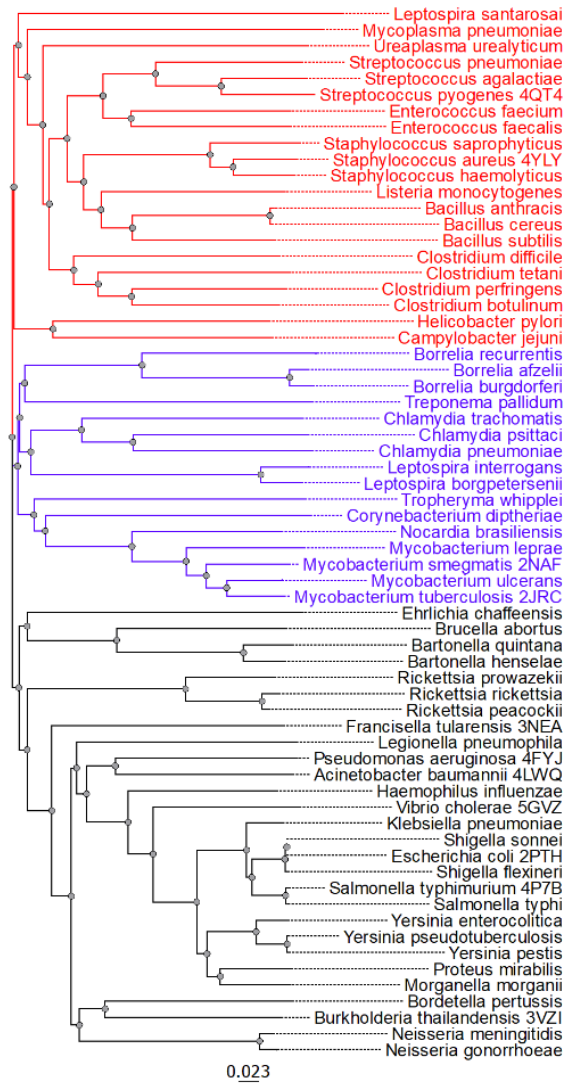

(A)

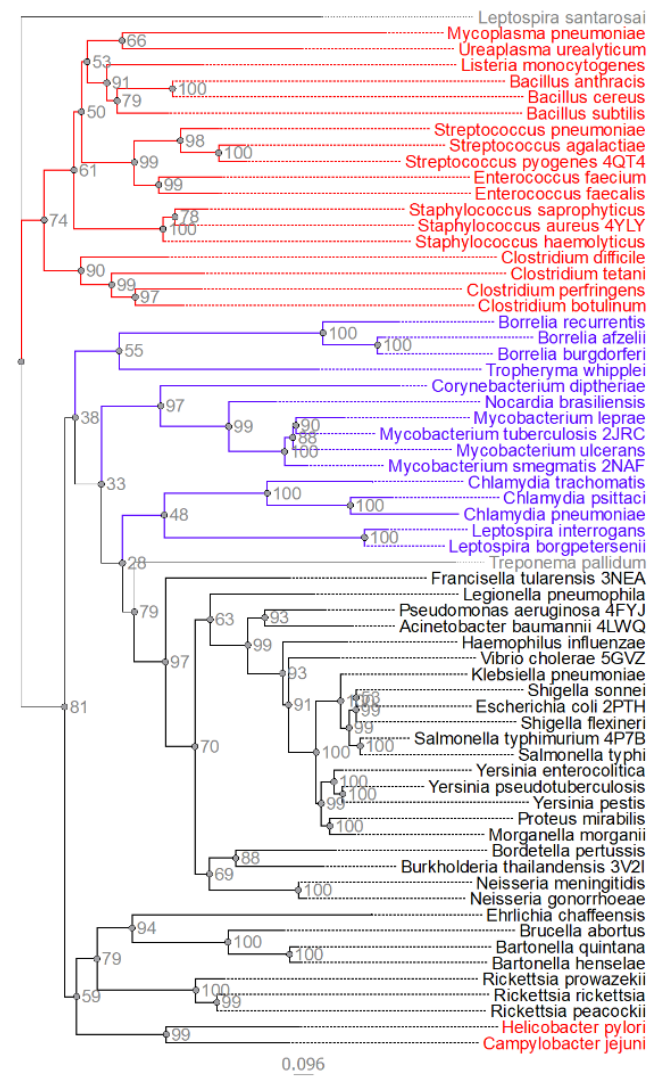

(B)

Figure 2. The Phylogenetic Relationships of Pth1 from Pathogenic Bacteria. (A) Shown are the simple phylogenetic relations for Pth1 from pathogenic bacteria. The intermediary Clade 2 is colored blue. Pth1 with known structures have the 4 character PDBID after the name. (B) Shown is the phylogenetic tree generated in IQTREE $[28,29]$ with bootstrap values indicated. Coloring reflects grouping identified in the simple phylogenetic analysis. Bootstrap values are shown in gray.
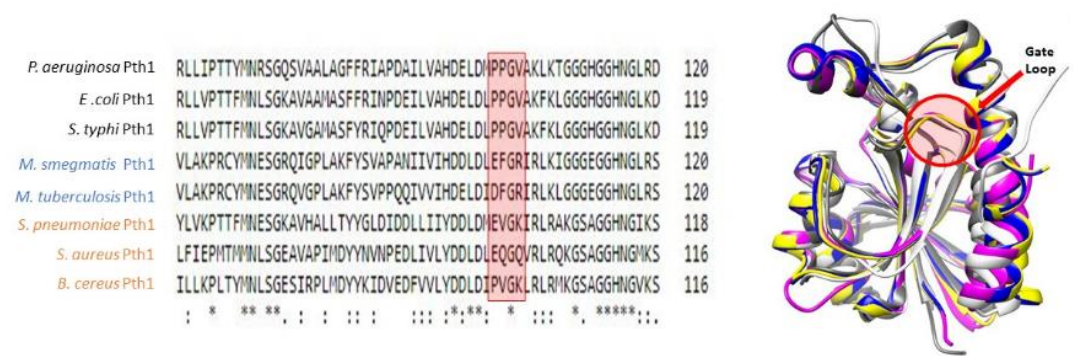

Figure 3. Gate Loop Region of Bacterial Pth1. (Left) Multiple sequence alignment of the gate loop region reveals a conserved motif within phylogenetic clades. * indicates identicle residues. (Right) The gate loop structure maintains a highly conserved fold following superimposition of crystal structures. 


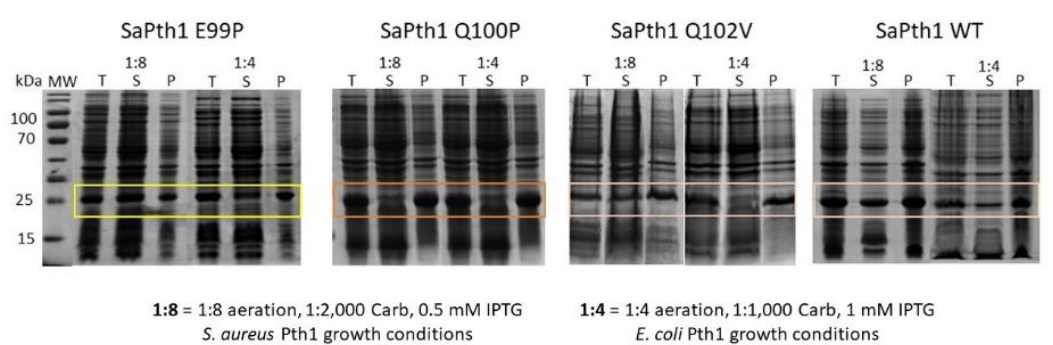

Figure 4. Gate Loop Residues Affect Pth1 Solubility. Solubility for residue changes in the Gate Loop are shown. Aeration is defined as the ratio of volume of culture media to flask volume. The total protein $(\mathrm{T})$, soluble fraction $(\mathrm{S})$ and insoluble pellet $(\mathrm{P})$ are shown for each construct and condition.

\subsection{Pth1 Natural Product Inhibition}

Given the past success of inhibiting Pth1 $[18,24,25]$ along with progress made to facilitate the discovery of the active compounds [31], we utilized natural products to qualitatively and semi-quantitatively characterize Pth1 inhibition, see Figure 5. Using a common panel of natural product extracts, inhibition of substrate cleavage was determined for Pth1 from the following species: Escherichia coli, Pseudomonas aeruginosa, Salmonella typhimurium (Clade 1), Mycobacterium tuberculosis (Clade 2), and Bacillus cereus and Staphylococcus aureus (Clade 3), see Figure 6. Of immediate interest, very different inhibition profiles were found for Pth1 from different pathogenic bacteria. While a finite number of homologs were tested for each clade and acknowledged for the following interpretation, the differences between homologs are clear. For some natural product extracts, like Ardisia compressa (extract \#3), Mandevilla veraguasenis (\#4), Exothea paniulata (\#5), and Inga sierra (\#6), Pth1 inhibition strictly followed the clade boundaries. These extracts only inhibited Clade 1 enzymes and the Clade 2 homolog Pth1 from M. tuberculosis. Extracts from Acacia aulacocarpa (\#15), Ocotea floribunda (\#16), and Urera caracasma (\#18) demonstrated more narrow-spectrum activity, inhibiting just PaPth1 within Clade 1. Similarly, the Albizia adenocephala extract (\#14) inhibited Pth1 from B. cereus and M. tuberculosis. From the susceptibility standpoint, Pth1 from B. cereus and S. aureus, both Clade 3 members tested, were the least susceptible Pth1 homologs to natural product inhibition, being inhibited by four and six natural products respectively. The most susceptible was Pth1 from P. aeruginosa, inhibited by 19 natural products. While it must be kept in mind that the inhibitory activity may not be due to a single component and that a limited number of Pth1 homologs were tested these results provide the first indication that narrow-spectrum Pth1 inhibition is possible and an evidence-based understanding of Pth1 small-molecule inhibition, directly countering the long-held idea that Pth1 sequence homology leads to uniform small-molecule inhibition.

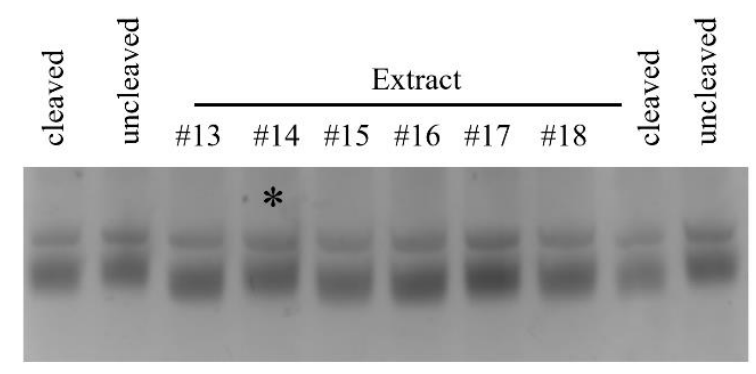

Figure 5. Natural Product Inhibition of B. cereus Pth1. Shown is an example of typical inhibition data, cleaved represents the positive control containing fully active Pth1 with no inhibitor. Uncleaved is the negative control, substrate peptidyl-tRNA with no Pth1. The * indicates inhibition by the natural product extract. The lower band is the substrate peptidyl-tRNA that exhibit migration differences based on cleavage state. The top band is 5S rRNA, an artifact of purification, that serves as an internal standard. 


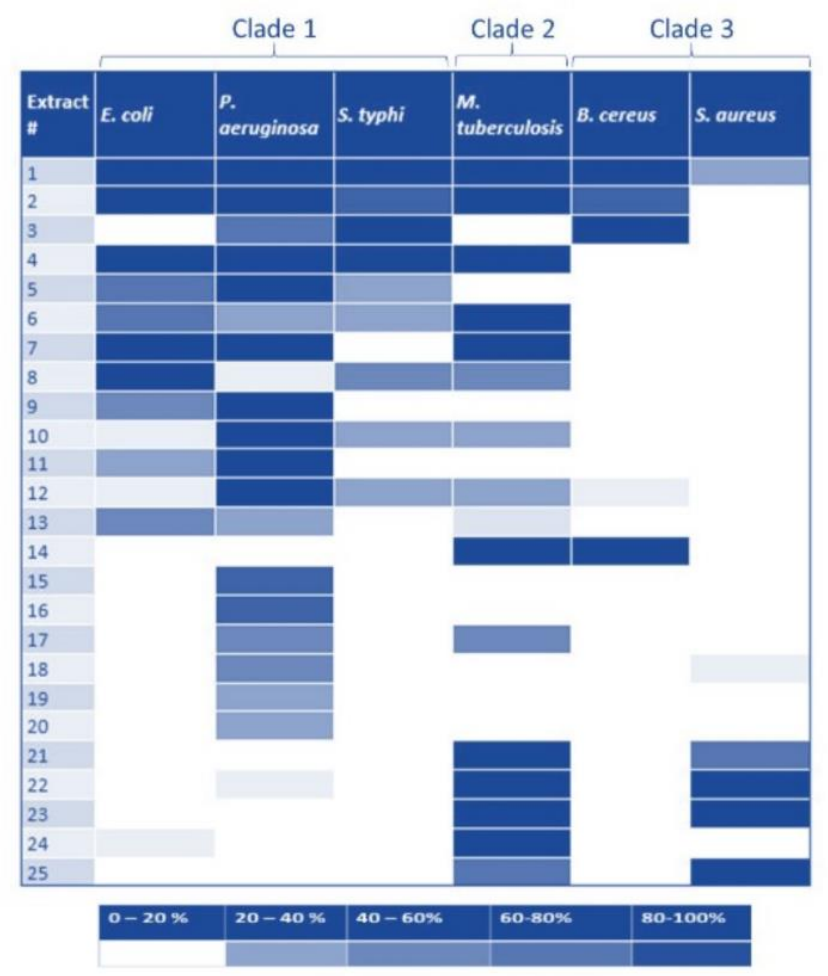

Figure 6. Natural Product Inhibition of Pth1 Spanning Phylogenetic Space. Inhibitory activity for a panel of natural product extracts tested for inhibition against Pth1 is shown. The degree of inhibition is shown at the bottom, with darker color indicating stronger inhibition.

\subsection{Enzyme Kinetic Parametrization}

The enzyme kinetic parameters also show a correlation to clade boundaries, see Figure 7 with typical data shown in Figure 8. For the Pth1 homologs tested it is clear that Clade 1 representatives have the lowest $V_{\max }$, highest $\mathrm{K}_{\mathrm{m}}$, and lowest $\mathrm{K}_{\text {cat }} / \mathrm{K}_{\mathrm{m}}$ with the opposite holding true for Clade 3 homologs. As for the phylogenetic characterization, Clade 2 Pth 1 kinetic parameters are intermediate between Clade 1 and Clade 3 homologs. While it appears the $\mathrm{K}_{\mathrm{cat}}$ is similar for all Pth1s, $\mathrm{K}_{\mathrm{m}}$ is an order of magnitude different with averages of $49 \mu \mathrm{M}$ for Clade 1, $17 \mu \mathrm{M}$ for Clade 2, and $9 \mu \mathrm{M}$ for Clade 3 . The differences in kinetic parameters between Clade 1 Pth1s and Clade 2 Pth1s as well as Clade 1 Pth1s and Clade 3 Pth1s were found to be statistically significant with a $p$-value of 0.02 and 0.05 respectively. The difference between Clade 2 and Clade 3 homologs was characterized by a $p$-value of 0.06 . Although only relative comparisons can be made due to the use of partial substrates and different assay conditions, the same trends in kinetic parameters were previously found for E. coli Pth1 [14,19], M. tuberculosis Pth1 [32], and S. aureus Pth1 [23]. Given the distinct amino acid differences in the gate loop region and effects on solubility, the E99P (S. aureus to P. aeruginosa) change was also examined for effects on kinetic parameters, see Figure $9 . K_{m}$ for this mutant was only half that of wild-type $S$. aureus $P$ th1 whereas $V_{\max }$ was relatively unchanged, resulting in a relatively low $p$-value of 0.09 when comparing $\mathrm{K}_{\mathrm{cat}} / \mathrm{K}_{\mathrm{m}}$. This demonstrates, at least in part, the effect residues in the gate loop have on enzymatic activity. 
A)

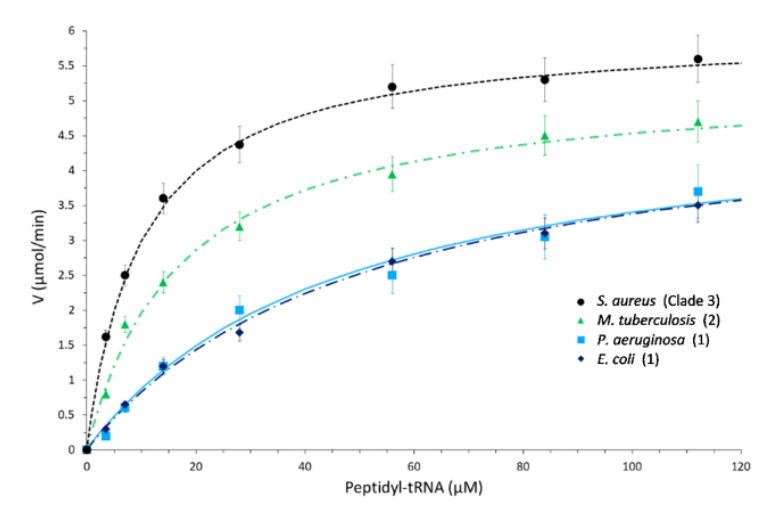

B)

\begin{tabular}{|c|c|c|c|c|}
\hline Pth1 Homolog & $\begin{array}{c}V_{\max } \\
\left(\mu M^{*} \min ^{-1}\right)\end{array}$ & $\begin{array}{c}\mathrm{K}_{\mathrm{m}} \\
(\mu \mathrm{M})\end{array}$ & $\begin{array}{l}K_{\text {cat }} \\
\left(s^{-1}\right)\end{array}$ & $\begin{array}{c}\mathbf{K}_{\text {cat }} / \mathbf{K}_{\mathrm{m}} \\
\left(\mu \mathbf{M}^{-1 *} \mathbf{s}^{-1}\right)\end{array}$ \\
\hline E. coli & $5.1 \pm 0.1$ & $51.0 \pm 3.0$ & $3.0 \times 10^{-3}$ & $5.9 \times 10^{-5}$ \\
\hline P. aeruginosa & $5.0 \pm 0.1$ & $47.0 \pm 0.9$ & $3.0 \times 10^{-3}$ & $6.3 \times 10^{-5}$ \\
\hline M. tuberculosis & $5.3 \pm 0.2$ & $17.0 \pm 2.2$ & $3.2 \times 10^{-3}$ & $1.9 \times 10^{-4}$ \\
\hline S. aureus & $6.0 \pm 0.1$ & $10.0 \pm 0.4$ & $3.6 \times 10^{-3}$ & $3.6 \times 10^{-4}$ \\
\hline B. cereus & $5.5 \pm 0.3$ & $8.0 \pm 1.0$ & $3.3 \times 10^{-3}$ & $4.1 \times 10^{-4}$ \\
\hline
\end{tabular}

Figure 7. Comparison of Kinetic Parameters for Pth1 from Different Phylogenetic Clades. (A) Plots of enzyme velocity versus substrate concentration are shown for Pth1 from E. coli, P. aeruginosa, M. tuberculosis, and S. aureus. The representative clade is indicated in parenthesis. (B) Table showing a summary of kinetic parameters for Pth1 tested.

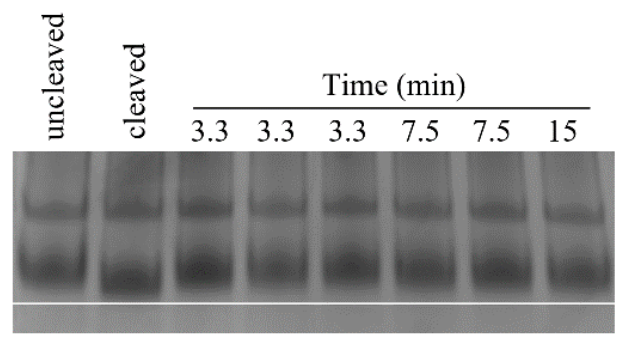

\begin{tabular}{|c|c|}
\hline Lane & $\%$ Cleaved \\
\hline 1 & 0 \\
\hline 2 & 100 \\
\hline $3,4,5$ & $37 \pm 3$ \\
\hline 6,7 & $48 \pm 2$ \\
\hline 8 & $76 \pm 5$ \\
\hline
\end{tabular}

Figure 8. S. aureus Pth1 Kinetic Data. Shown is a representative time course of substrate cleavage by Pth1 from S. aureus. Uncleaved indicates the negative control, enzyme substrate or peptidyl-tRNA. Cleaved indicates the positive control, enzyme product or peptidyl-tRNA fully cleaved to free tRNA. A white line was added to better visualize the band shift. To the right is a table that shows the percent of substrate cleaved \pm standard deviation, calculated from migration distance. 
A)

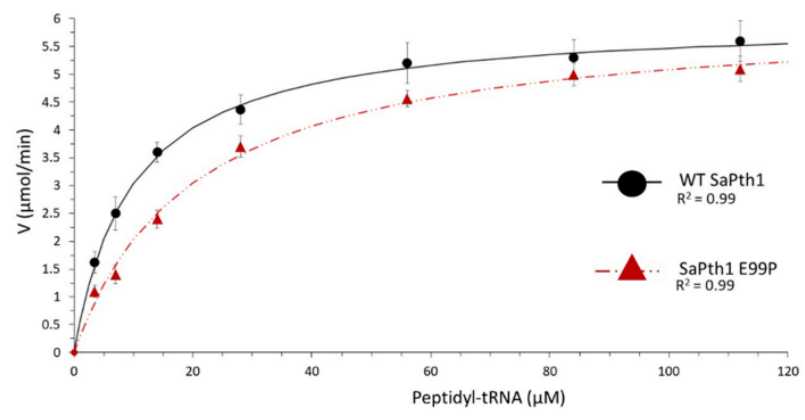

B)

\begin{tabular}{|c|c|c|c|c|}
\hline Sa Pth1 & $\begin{array}{c}\mathbf{V}_{\max } \\
\left(\mu \mathbf{M}^{*} \mathbf{m i n}^{-1}\right)\end{array}$ & $\begin{array}{c}\mathbf{K}_{\mathrm{m}} \\
(\boldsymbol{\mu M})\end{array}$ & $\begin{array}{c}\mathbf{K}_{\text {cat }} \\
\left(\mathbf{s}^{-1}\right)\end{array}$ & $\begin{array}{c}\mathbf{K}_{\text {cat }} / \mathbf{K}_{\mathrm{m}} \\
\left(\boldsymbol{\mu} \mathbf{M}^{-1 *} \mathbf{s}^{-1}\right)\end{array}$ \\
\hline Wild-type & $6.0 \pm 0.1$ & $10.0 \pm 0.4$ & $3.6 \times 10^{-3}$ & $3.6 \times 10^{-4}$ \\
\hline E99P & $6.1 \pm 0.2$ & $20.0 \pm 1.7$ & $3.6 \times 10^{-3}$ & $1.8 \times 10^{-4}$ \\
& & & & \\
\hline
\end{tabular}

Figure 9. S. aureus Pth1 Gate Loop Mutation Affects $K_{m}$ but not $V_{\max }$ or $K_{\text {cat }}$. (A) The velocity of substrate cleavage for wild-type S. aureus Pth1 (black circles) is compared to the mutant E99P S. aureus Pth1 (red triangles). (B) Table showing a summary of kinetic parameters.

\section{Discussion}

In the past, interest in Pth1 as an antibiotic target was mitigated by the high degree of amino acid sequence homology and the accompanying supposition that only broadspectrum inhibition was possible. Further, given that there exists a human homolog, it was supposed that cytotoxicity would be a significant issue due to the essential function of Pth1 in bacteria. Subsequently, yeast knockout studies showed recycling peptidyl-tRNA in eukaryotes is not critically dependent on Pth1 [10]. Herein we further understanding Pth1 and, for the first time, demonstrate that Pth1 from dissimilar bacterial species can be differentially inhibited by small molecules. Thus, the possibility for narrow-spectrum inhibition and considerable potential for small-molecule inhibition exists, both advancing Pth1 antibiotic development.

Phylogenetic characterization of Pth1 reveals the presence of at least two distinct clades. A correlation between clade and Gram specificity is present, but it is unclear as to the origin. One possibility is tRNA methylation, which is known to be different between Gram-positive and Gram-negative bacteria [33-36]. However, it is not clear that the methylation affects the acceptor stem which appears to be most closely involved in substrate binding. Yet, at least one Gram-positive bacterial species is known to possess methylation in the acceptor stem [37]. While this may lend itself to recognition via a scanning mechanism [16] with methylation affecting binding, the validity of this model still needs proof in an in vivo setting. Given that the peptidyl-tRNA used in these studies are from a Gram-negative strain, it would be of interest to characterize kinetics using peptidyl-tRNA from a Gram-positive source.

While the Gram specificity may be unclear, it is clear that the residues in the gate loop are largely responsible for differences in $\mathrm{K}_{\mathrm{m}}$. Homologs with acidic aspartate or glutamate residues (Clades 2 and 3) versus proline (Clade 1) at position 99, had relatively smaller $\mathrm{K}_{\mathrm{m}}$ values equating to a higher affinity interaction and improved catalytic efficiency. This may be a result of dynamic constraints caused by the proline residue or negative charge of the acidic residues, though further studies will be needed to clarify this issue. 
In regards to small-molecule inhibition, all Pth1 homologs tested show some degree of narrow-spectrum inhibition. This counters the assumption that the high degree of sequence homology would lead to similar small-molecule inhibition. Moreover, it underscores the advantage of studying homologs from multiple species to get a better understanding of the enzyme family as a whole, not relying on one sequence and extrapolation. Inhibition following clade boundaries could also be distinguished. Regrettably, homologs in Clade 1 (Gram-negative) were most susceptible to inhibition, whereas Clade 3 homologs (Grampositive) showed the least susceptibility. While this has nothing to do with the more abundant extracellular peptidoglycan, it correlates with the greater difficulty of targeting Gram-positive bacteria with small-molecule inhibitors. The differences in clade inhibition do open other possibilities. While purely speculative, one could imagine engineering major gut species to have Pth 1 from both Clade 1 and Clade 3. Thus when administering Pth1 antibiotics, one could at least partially circumvent the side effects of eliminating beneficial species in the host GI tract by also administering probiotics with the other Clade Pth1 (that would be resistant to the systemic Pth1 antibiotic targeting the pathogen). Regardless, these findings demonstrate the potential not only for broad-spectrum inhibition of Pth1, but also narrow-spectrum inhibition.

The enzyme kinetics characterization was performed using bulk peptidyl-tRNA, the same substrate as that for inhibition studies. Thus, the results are interpreted with the caveat that a mixture of tRNAs with variable peptides was used. Nevertheless, the very similar $\mathrm{K}_{\text {cat }}$ values for homologs across phylogenetic space indicate the chemistry of the reaction was mostly unchanged. This is expected given the absolutely conserved catalytic histidine and highly conserved supporting residues. However, $\mathrm{K}_{\mathrm{m}}$ and therefore $\mathrm{K}_{\mathrm{cat}} / \mathrm{K}_{\mathrm{m}}$ for each homolog do show significant differences between Clade 1 and Clade $3 . K_{m}$ and $\mathrm{K}_{\mathrm{cat}} / \mathrm{K}_{\mathrm{m}}$ for the $M$. tuberculosis Pth1, the only Clade 2 representative, are intermediate, between Clade 1 and 3 values. These findings and the overall trend in $K_{m}$ are consistent with previously published results [14,23,32].

Overall, it is clear that there are significant differences between Pth1 across bacterial species. Even with the high degree of sequence homology, the different kinetic parameters indicate that while $V_{\max }$, and thereby the catalytic reaction, is mostly unchanged, substrate binding is different given the large differences in $\mathrm{K}_{\mathrm{m}}$. The difference in binding substrate agrees with the differential small-molecule inhibition observed for natural products. These observations give a clear indication that selective Pth1 inhibition is possible, elevating Pth1 as a viable antibiotic target.

While the structural knowledgebase of Pth1 now spans phylogenetic space, the majority of crystal structures come from Clade 1 Pth1 enzymes. Additionally, the resolution of crystal structures from Clade 1 Pth 1 (typically below $1.7 \AA$ ) is considerably better than for those from Clade 3 (2.7 and 2.2 $\AA$ ). A possible explanation may be the clade-specific correlation with solubility so simply explained by the ease of preparation (from our personal experience and as intuited from the literature). The difficulty and lower resolution of structures from Clade 3 may also be attributed to the gate loop. If the presence of a proline alters dynamics or impacts sampling of conformational space, differences in crystallization and uniformity of crystallization can be readily explained. This may also be related to the difficulty in crystallizing Pth1 with small-molecule inhibitors bound. We observed that soaking in does not lead to occupancy in the binding site, even for known competitive inhibitors. Similarly, co-crystallization significantly changes the crystallization conditions. Thus it appears a lock-and-key fit is not supported for Pth1. This also agrees with recent preliminary computational efforts for which high throughput screening to the apo structure does not lead to any significant enrichment of higher affinity binding. Nor does the computational docking of known Pth1 inhibitors agree with experimentally derived binding affinities. Thus it is suspected that a yet unknown conformation change occurs upon high-affinity binding in the active site. 


\section{Materials and Methods}

\subsection{Phylogenetic Characterization}

Using the EMBL-EBI bioinformatics tools [38], multiple amino acid sequences were aligned using MUSCLE [39] and simple phylogenetic analysis was performed by the neighborjoining method [40]. More in-depth phylogeny was obtained using IQ-TREE [28,29] that employed ModelFinder [41] to find the best substitution model. Bootstrap values were determined from 1000 replicates by the ultrafast bootstrap [42]. SH-aLRT analysis [43] was also performed. The Newick format generated trees from both tools were visualized in UGENE [44].

\subsection{Pth1 Expression and Purification}

Pth1 was expressed and purified as previously reported [12,45-47]. Briefly, for all constructs other than M. tuberculosis that was a kind gift from Dr. Vijayan [48], the E. coli codon-optimized Pth1 sequence was cloned into a $\mathrm{pKQV} 4$ expression vector which introduced an $\mathrm{N}$-terminal hexahistidine tag. After transformation into chemically competent BL21(DE3)pLysS E. coli, individual colonies were selected from plates. Cells were typically grown at $37^{\circ} \mathrm{C}$ in LB media containing $100 \mathrm{mg} / \mathrm{mL}$ carbenicillin, induced with $1 \mathrm{mM}$ (final concentration) IPTG at an $\mathrm{OD}_{600}$ of 0.7 , and harvested after $6 \mathrm{~h}$. However, to obtain soluble S. aureus Pth1, conditions were optimized to $20 \mathrm{mg} / \mathrm{mL}$ carbenicillin, $0.5 \mathrm{mM}$ IPTG at and induction $\mathrm{OD}_{600}$ of 0.9 , the post-induction temperature was shifted to $12{ }^{\circ} \mathrm{C}$, and cells were harvested after $16 \mathrm{~h}$. Cells were then pelleted and stored frozen at $-80^{\circ} \mathrm{C}$ until lysis and purification via metal chelation chromatography using a $\mathrm{Ni}^{2+}$ bound His-Trap Fast Flow column (GE Lifesciences, Pittsburgh, PA, USA). Purified Pth1 was dialyzed in the appropriate buffer and quantified using UV spectroscopy. Gel images for the Pth1 enzymes used in this manuscript are shown in Figure S1.

For the solubility studies, Pth1 constructs were grown as indicated. Cells were harvested at equal optical density and lysed. Gel samples were taken from the entire cell lysate to show the total protein content. The cell lysate was centrifuged as described in the previous purification references and the supernatant, representing soluble protein, was separated from the pellet which contained the insoluble proteins. Gel samples were prepared from both the soluble and insoluble protein, with the insoluble fraction being resuspended in an equal volume of the buffer as the soluble fraction, so a direct comparison of Pth1 content could be made from band intensity.

\subsection{Site-Directed Mutagenesis of the S. aureus Pth1 Gate Loop}

Mutations were introduced to the $\mathrm{pKQV} 4$ plasmid possessing S. aureus Pth1 using the QuikChange Lightning (Stratagene, San Diego, CA, USA) site-directed mutagenesis kit following the manufacturer's protocols and primer design. S. aureus Pth1 mutations included E99P, Q100P, and Q102V (E. coli Pth1 numbering used throughout). S. aureus Pth1 mutants were transformed into chemically competent BL21(DE3)pLys E. coli and grown at typical and S. aureus Pth1 optimized conditions (both described above).

\subsection{Pth1 Enzyme Activity}

Pth1 activity, or cleavage of substrate peptidyl-tRNA, was evaluated as previously reported [22]. Briefly, the desired amount of Pth1 was incubated for $30 \mathrm{~min}$ at room temperature with $1.5 \mu \mathrm{g}$ of bulk peptidyl-tRNA isolated as described in [49]. The working buffer was $20 \mathrm{mM}$ Tris-acetate $\mathrm{pH}$ 8.0, $20 \mathrm{mM}$ magnesium acetate, $40 \mathrm{mM}$ ammonium acetate. The reaction was quenched with a $2 \mathrm{X}$ loading dye $(100 \mathrm{mM}$ sodium acetate, $35 \mathrm{mM}$ urea, $0.0025 \mathrm{~g}$ bromophenol blue, DEPC-treated water to $5 \mathrm{~mL}$ total volume) and samples run at $100 \mathrm{~V}$ on an $8 \%$ acid-urea minigel. After staining with methylene blue, gels were analyzed and substrate cleavage quantitated. In more detail, quantitation entailed calculating the percentage of the cleaved substrate as measured by migration differences observed on acid-urea gels, using the uncleaved control $(0 \%$ cleaved, $100 \%$ inhibited, largest substrate, least migration) and fully cleaved control (100\% cleaved, $0 \%$ inhibited, 
smallest substrate, most migration) as bounds [22]. All values were determined as averages of three measurements with the error being the standard deviation. Measurement error, in agreement with results from the previously published method, was less than $5 \%$ in all cases. It should be noted that there are two bands in the activity assay. The lower band is the peptidyl-tRNA substrate which can be cleaved and shows a difference in migration distance. The top band in an artifact, presumably the 5S rRNA fragment, that is a remnant of the purification. The $5 S$ fragment does not get cleaved, but is utilized as an internal standard for each lane.

\subsection{Natural Product Inhibition}

Natural product extracts were obtained from tropical rainforest plant material collected in north Queensland, Australia [50,51], Monteverde, Costa Rica [52], Matabeleland, Zimbabwe, and Abaco Island, Bahamas [53]. Plant material was crushed and effused with solvent, see Figure S2. The solubilized fraction was separated from bulk plant material, lyophilized and then stored frozen. Thawed pellets of the crude plant extracts were resuspended in DMSO to form 1\% $w / v$ solutions, the final vehicle for inhibition studies. For inhibition studies, these crude extracts were substituted for water in the previously described Pth1 enzyme activity reactions and all controls were run with volumes of DMSO equal to those in the samples containing natural product inhibitors. Thus the only difference was the presence of natural product extract. It should be noted that Pth1 activity is known to be unaffected by DMSO concentrations exceeding 20\% [22], the upper limit used herein. The inhibition reported (Figure 6) was determined as a percentage of inhibited cleavage, described in the previous section. The measurement was an average of three independent measurements. For graphical presentation, the degree of inhibition was binned into the appropriate pentile. As before, all errors were found to be less than $5 \%$ as determined from the standard deviation.

\subsection{Pth1 Kinetic Analysis}

Kinetic data were acquired using the same enzyme activity assay described above. The final concentration of Pth1 was $30 \mu \mathrm{M}$ and all reactions were run at $20^{\circ} \mathrm{C}$. Reactions were carried out at 1:0.13, 1:0.25, 1:0.5, 1:1, 1:2, 1:3, and 1:4 Pth1:peptidyl-tRNA molar ratios. The concentration of the original stock of peptidyl-tRNA was determined using $A_{260} / A_{280}$ ratio. The solution was subsequently diluted such that equal volumes of the substrate were added to the enzyme reaction mixture. Reactions were quenched at 5-10 min intervals with ending times (30-50 min) dependent on substrate concentration. Products of the reaction mixtures were separated on acid urea minigels and analyzed as described above. From plots of product vs. time, $\mathrm{V}_{\mathrm{o}}$ was determined from the initial tangent line slope for each substrate concentration. The assay was repeated in triplicate for all time intervals and peptidyl-tRNA concentrations used. Kinetic parameters were determined using previously reported approaches [54].

\subsection{Statistical Analysis}

Statistical analysis for determining differences in solubility of the expressed S. aureus WT and mutants was performed using densitometry. Fraction soluble was calculated from the ratio of the normalized soluble Pth1 band to the Pth1 total band. The results were obtained by analyzing samples from three separate measurements each and used to calculate $p$-values using a two-tailed Student $t$-test.

Statistical analysis comparing Pth1 kinetic parameters from different clades as well as WT S. aureus Pth1 and S. aureus E99P Pth1 was carried out using one-way ANOVA analysis with $\mathrm{K}_{\mathrm{cat}} / \mathrm{K}_{\mathrm{m}}$ and $\mathrm{K}_{\mathrm{m}}$ values for each enzyme being treated as the independent variables to determine statistical significance between each clade. For both tests, $p$-values smaller than 0.05 indicated a statistically significant difference. 


\section{Conclusions}

This report demonstrates the advantage of characterizing multiple homologs, spanning phylogenetic space in antibiotic development. This is particularly relevant for smallmolecule inhibition where characterization of only one member of an enzyme family, even one with high homology, may not be adequate. For Pth1, this analysis opens the doors to many different avenues of inhibitor development. Most significant is that both broad and narrow-spectrum inhibition is possible for Pth1. Coupled with phylogenetic characterization and kinetic characterization, the tremendous promise to antibiotic development against this new target is uncovered. The possibility of narrow-spectrum inhibition has the advantages of diminishing the spread of resistance across multiple bacterial species and greater limiting detrimental effects on the host microbiome [55]. Moreover, this and other reports $[18,24,25]$ demonstrate the potential for natural product inhibition targeting Pth1. With a significant number of current therapeutics tracing roots to natural products coupled with the support of the large structural knowledgebase existing for Pth1, novel drug discovery targeting Pth1 is poised for significant breakthroughs.

Supplementary Materials: The following are available online, Figure S1: Gel Images of Purified Pth1 and Figure S2: Natural Product Extracts.

Author Contributions: Conceptualization, R.L.M.; methodology, W.B.H., J.N.W., H.M.; formal analysis and investigation, D.S.S., S.S.G., W.B.H., M.D.K., J.N.W.; writing-original draft preparation, D.S.S., R.L.M.; writing—review and editing, D.S.S., J.N.W., M.D.K., H.M., R.L.M.; supervision, H.M., R.L.M.; project administration, H.M., R.L.M.; funding acquisition, R.L.M. All authors have read and agreed to the published version of the manuscript.

Funding: Research reported in this publication was supported in part by the NIGMS of the National Institutes of Health under award number R15GM119052. The content is solely the responsibility of the authors and does not necessarily represent the official views of the National Institutes of Health. The APC was funded by R.L.M.

Institutional Review Board Statement: Not applicable.

Informed Consent Statement: Not applicable.

Data Availability Statement: The data presented in this sudy are available on request from the corresponding author.

Acknowledgments: The authors thank William Setzer for providing natural product extracts and the late Joe Leahy for initial guidance in phylogenetic characterization. The authors also thank Luis Cruz-Vera for many useful discussions from his decades of Pth1 experience.

Conflicts of Interest: The authors declare no conflict of interest.

Sample Availability: Samples of plasmids are available from the authors.

\section{References}

1. Jørgensen, F.; Kurland, C.G. Processivity errors of gene expression in Escherichia coli. J. Mol. Biol. 1990, 215, 511-521. [CrossRef]

2. Kurland, C.G.; Ehrenberg, M. Constraints on the Accuracy of Messenger Rna Movement. Q. Rev. Biophys. 1985, 18, 423-450. [CrossRef] [PubMed]

3. Manley, J.L. Synthesis and degradation of termination and premature-termination fragments of $\beta$-galactosidase in vitro and in vivo. J. Mol. Biol. 1978, 125, 407-432. [CrossRef]

4. Cruz-Vera, L.R.; Hernández-Ramón, E.; Pérez-Zamorano, B.; Guarneros, G. The rate of peptidyl-tRNA dissociation from the ribosome during minigene expression depends on the nature of the last decoding interaction. J. Biol. Chem. 2003, 278, 26065-26070. [CrossRef]

5. Hernández-Sánchez, J.; Valadez, J.G.; Herrera, J.V.; Ontiveros, C.; Guarneros, G. $\lambda$ bar minigene-mediated inhibition of protein synthesis involves accumulation of peptidyl-tRNA and starvation for tRNA. EMBO J. 1998, 17, 3758-3765. [CrossRef]

6. Tenson, T.; Vega Herrera, J.; Kloss, P.; Guarneros, G.; Mankin, A.S. Inhibition of translation and cell growth by minigene expression. J. Bacteriol. 1999, 181, 1617-1622. [CrossRef]

7. Heurgué-Hamard, V.; Mora, L.; Guarneros, G.; Buckingham, R.H. The growth defect in Escherichia coli deficient in peptidyl-tRNA hydrolase is due to starvation for Lys-tRNA(Lys). EMBO J. 1996, 15, 2826-2833. [CrossRef]

8. Menninger, J.R. Accumulation of peptidyl tRNA is lethal to Escherichia coli. J. Bacteriol. 1979, 137, 694-696. [CrossRef] 
9. Menez, J.; Buckingham, R.H.; De Zamaroczy, M.; Campelli, C.K. Peptidyl-tRNA hydrolase in Bacillus subtilis, encoded by spoVC, is essential to vegetative growth, whereas the homologous enzyme in Saccharomyces cerevisiae is dispensable. Mol. Microbiol. 2002, 45, 123-129. [CrossRef]

10. Rosas-Sandoval, G.; Ambrogelly, A.; Rinehart, J.; Wei, D.; Cruz-Vera, L.R.; Graham, D.E.; Stetter, K.O.; Guarneros, G.; Söll, D. Orthologs of a novel archaeal and of the bacterial peptidyl-tRNA hydrolase are nonessential in yeast. Proc. Natl. Acad. Sci. USA 2002, 99, 16707-16712. [CrossRef]

11. Goodall, J.J.; Chen, G.J.; Page, M.G.P. Essential Role of Histidine 20 in the Catalytic Mechanism of Escherichia coli Peptidyl-tRNA Hydrolase. Biochemistry 2004, 43, 4583-4591. [CrossRef]

12. Pulavarti, S.V.S.R.K.; Jain, A.; Prakash Pathak, P.; Mahmood, A.; Arora, A. Solution Structure and Dynamics of Peptidyl-tRNA Hydrolase from Mycobacterium tuberculosis H37Rv. J. Mol. Biol. 2008, 378, 165-177. [CrossRef] [PubMed]

13. Kabra, A.; Shahid, S.; Pal, R.K.; Yadav, R.; Rama Krishna Pulavarti, S.V.S.; Jain, A.; Tripathi, S.; Arora, A. Unraveling the stereochemical and dynamic aspects of the catalytic site of bacterial peptidyl-tRNA hydrolase. RNA 2017, 23. [CrossRef] [PubMed]

14. Giorgi, L.; Plateau, P.; O’Mahony, G.; Aubard, C.; Fromant, M.; Thureau, A.; Grøtli, M.; Blanquet, S.; Bontems, F. NMR-based substrate analog docking to escherichia coli peptidyl-tRNA hydrolase. J. Mol. Biol. 2011, 412, 619-633. [CrossRef] [PubMed]

15. Giorgi, L.; Bontems, F.; Fromant, M.; Aubard, C.; Blanquet, S.; Plateau, P. RNA-binding site of escherichia coli peptidyl-tRNA hydrolase. J. Biol. Chem. 2011, 286, 39585-39594. [CrossRef] [PubMed]

16. Ito, K.; Murakami, R.; Mochizuki, M.; Qi, H.; Shimizu, Y.; Miura, K.I.; Ueda, T.; Uchiumi, T. Structural basis for the substrate recognition and catalysis of peptidyl-tRNA hydrolase. Nucleic Acids Res. 2012, 40. [CrossRef] [PubMed]

17. Hames, M.C.; McFeeters, H.; Blake Holloway, W.; Stanley, C.B.; Urban, V.S.; McFeeters, R.L. Small molecule binding, docking, and characterization of the interaction between Pth1 and peptidyl-tRNA. Int. J. Mol. Sci. 2013, 14, 22741-22752. [CrossRef] [PubMed]

18. Ferguson, P.P.; Holloway, W.B.; Setzer, W.N.; McFeeters, H.; McFeeters, R.L. Small molecule docking supports broad and narrow spectrum potential for the inhibition of the novel antibiotic target bacterial Pth1. Antibiotics 2016, 5, 16. [CrossRef] [PubMed]

19. Shiloach, J.; Bauer, S.; De Groot, N.; Lapidot, Y. The influence of the peptide chain length on the activity of peptidyl-tRNA hydrolase from E. coli. Nucleic Acids Res. 1975, 2. [CrossRef]

20. McFeeters, R.L. Recent Antimicrobial Developments Targeting Peptidyl-tRNA Hydrolases. JSM Biotechnol. Biomed. Eng. 2013, 1,1006-1008.

21. McFeeters, H.; McFeeters, R.L. Current Methods for Analysis of Enzymatic Peptidyl-tRNA Hydrolase. J. Anal. Bioanal. Tech 2014, 5. [CrossRef]

22. Holloway, W.B.; McFeeters, H.; Powell, A.; Nidadavolu, G.S.; McFeeters, R.L. A Highly Adaptable Method for Quantification of Peptidyl-tRNA Hydrolase Activity. J. Anal. Bioanal. Tech. 2015, 6. [CrossRef]

23. Bonin, P.D.; Erickson, L.A. Development of a fluorescence polarization assay for peptidyl-tRNA hydrolase. Anal. Biochem. 2002, 306. [CrossRef]

24. Harris, S.M.; McFeeters, H.; Ogungbe, I.V.; Cruz-Vera, L.R.; Setzer, W.N.; Jackes, B.R.; McFeeters, R.L. Peptidyl-tRNA hydrolase screening combined with molecular docking reveals the antibiotic potential of Syzygium johnsonii bark extract. Nat. Prod. Commun. 2011, 6. [CrossRef]

25. McFeeters, H.; Gilbert, M.J.; Thompson, R.M.; Setzer, W.N.; Cruz-Vera, L.R.; McFeeters, R.L. Inhibition of essential bacterial peptidyl-tRNA hydrolase activity by tropical plant extracts. Nat. Prod. Commun. 2012, 7. [CrossRef]

26. Wu, S.; Yang, L.; Gao, Y.; Liu, X.; Liu, F. Multi-channel counter-current chromatography for high-throughput fractionation of natural products for drug discovery. J. Chromatogr. A 2008, 1180. [CrossRef]

27. Newman, D.J.; Cragg, G.M.; Snader, K.M. Natural products as sources of new drugs over the period 1981-2002. J. Nat. Prod. 2003, 66, 1022-1037. [CrossRef] [PubMed]

28. Nguyen, L.T.; Schmidt, H.A.; Von Haeseler, A.; Minh, B.Q. IQ-TREE: A fast and effective stochastic algorithm for estimating maximum-likelihood phylogenies. Mol. Biol. Evol. 2015, 32, 268-274. [CrossRef] [PubMed]

29. Trifinopoulos, J.; Nguyen, L.T.; von Haeseler, A.; Minh, B.Q. W-IQ-TREE: A fast online phylogenetic tool for maximum likelihood analysis. Nucleic Acids Res. 2016, 44, W232-W235. [CrossRef] [PubMed]

30. Cruz-Vera, L.R.; Toledo, I.; Hernández-Sánchez, J.; Guarneros, G. Molecular basis for the temperature sensitivity of Escherichia coli pth(Ts). J. Bacteriol. 2000, 182. [CrossRef] [PubMed]

31. Sethi, H.S.; Osier, J.L.; Burks, G.L.; Lamar, J.F.; McFeeters, H.; McFeeters, R.L. Expedited isolation of natural product peptidyltRNA hydrolase inhibitors from a Pth1 affinity column. AIMS Mol. Sci. 2017, 4, 175-184. [CrossRef]

32. Bal, N.C.; Agrawal, H.; Meher, A.K.; Arora, A. Characterization of peptidyl-tRNA hydrolase encoded by open reading frame Rv1014c of Mycobacterium tuberculosis H37Rv. Biol. Chem. 2007, 388. [CrossRef]

33. Klagsbrun, M. An evolutionary study of the methylation of transfer and ribosomal ribonucleic acid in prokaryote and eukaryote organisms. J. Biol. Chem. 1973, 248, 2612-2620. [CrossRef]

34. Vani, B.R.; Ramakrishnan, T.; Taya, Y.; Noguchi, S.; Yamaizumi, Z.; Nishimura, S. Occurrence of 1-methyladenosine and absence of ribothymidine in transfer ribonucleic acid of Mycobacterium smegmatis. J. Bacteriol. 1979, 137. [CrossRef] [PubMed]

35. Bocchetta, M.; Xiong, L.; Mankin, A.S. 23S rRNA positions essential for tRNA binding in ribosomal functional sites. Proc. Natl. Acad. Sci. USA 1998, 95. [CrossRef] [PubMed] 
36. Liu, M.; Douthwaite, S. Methylation at nucleotide G745 or G748 in 23 S rRNA distinguishes Gram-negative from Gram-positive bacteria. Mol. Microbiol. 2002, 44. [CrossRef] [PubMed]

37. Boccaletto, P.; MacHnicka, M.A.; Purta, E.; Pitkowski, P.; Baginski, B.; Wirecki, T.K.; De Crécy-Lagard, V.; Ross, R.; Limbach, P.A.; Kotter, A.; et al. MODOMICS: A database of RNA modification pathways. 2017 update. Nucleic Acids Res. 2018, 46. [CrossRef] [PubMed]

38. Chojnacki, S.; Cowley, A.; Lee, J.; Foix, A.; Lopez, R. Programmatic access to bioinformatics tools from EMBL-EBI update: 2017. Nucleic Acids Res. 2017, 45. [CrossRef]

39. Edgar, R.C. MUSCLE: Multiple sequence alignment with high accuracy and high throughput. Nucleic Acids Res. 2004, 32. [CrossRef]

40. Nei, M.; Saitou, N. The neighbor-joining method: A new method for reconstructing phylogenetic trees. Mol. Biol. Evol. 1987, 4, 406-425.

41. Kalyaanamoorthy, S.; Minh, B.Q.; Wong, T.K.F.; Von Haeseler, A.; Jermiin, L.S. ModelFinder: Fast model selection for accurate phylogenetic estimates. Nat. Methods 2017, 14, 587-589. [CrossRef]

42. Hoang, D.T.; Chernomor, O.; Von Haeseler, A.; Minh, B.Q.; Vinh, L.S. UFBoot2: Improving the ultrafast bootstrap approximation. Mol. Biol. Evol. 2018, 35, 518-522. [CrossRef]

43. Guindon, S.; Dufayard, J.F.; Lefort, V.; Anisimova, M.; Hordijk, W.; Gascuel, O. New algorithms and methods to estimate maximum-likelihood phylogenies: Assessing the performance of PhyML 3.0. Syst. Biol. 2010, 59, 307-321. [CrossRef]

44. Okonechnikov, K.; Golosova, O.; Fursov, M.; Varlamov, A.; Vaskin, Y.; Efremov, I.; German Grehov, O.G.; Kandrov, D.; Rasputin, K.; Syabro, M.; et al. Unipro UGENE: A unified bioinformatics toolkit. Bioinformatics 2012, 28, 1166-1167. [CrossRef]

45. Hughes, R.C.; McFeeters, H.; Coates, L.; McFeeters, R.L. Recombinant production, crystallization and X-ray crystallographic structure determination of the peptidyl-tRNA hydrolase of Pseudomonas aeruginosa. Acta Crystallogr. Sect. F Struct. Biol. Cryst. Commun. 2012, 68. [CrossRef]

46. Taylor-Creel, K.; Hames, M.C.; Holloway, W.B.; McFeeters, H.; Mcfeeters, R.L. Expression, purification, and solubility optimization of peptidyl-tRNA hydrolase 1 from Bacillus cereus. Protein Expr. Purif. 2014, 95. [CrossRef]

47. Vandavasi, V.; Taylor-Creel, K.; McFeeters, R.L.; Coates, L.; McFeeters, H. Recombinant production, crystallization and X-ray crystallographic structure determination of peptidyl-tRNA hydrolase from Salmonella typhimurium. Acta Crystallogr. Sect. F Struct. Biol. Commun. 2014, 70. [CrossRef] [PubMed]

48. Selvaraj, M.; Singh, N.S.; Roy, S.; Sangeetha, R.; Varshney, U.; Vijayan, M. Cloning, expression, purification, crystallization and preliminary X-ray analysis of peptidyl-tRNA hydrolase from Mycobacterium tuberculosis. Acta Crystallogr. Sect. F Struct. Biol. Cryst. Commun. 2006, 62, 913-915. [CrossRef] [PubMed]

49. Varshney, U.; Lee, C.P.; RajBhandary, U.L. Direct analysis of aminoacylation levels of tRNAs in vivo: Application to studying recognition of Escherichia coli initiator tRNA mutants by glutaminyl-tRNA synthetase. J. Biol. Chem. 1991, 266, 24712-24718. [CrossRef]

50. Setzer, M.C.; Setzer, W.N.; Jackes, B.R.; Gentry, G.A.; Moriarity, D.M. The medicinal value of tropical rainforest plants from Paluma, North Queensland, Australia. Pharm. Biol. 2001, 39. [CrossRef]

51. Setzer, M.C.; Schmidt, J.M.; Irvine, A.K.; Jackes, B.R.; Setzer, W.N. Biological activity of rainforest plant extracts from Far North Queensland, Australia. Aust. J. Med. Herbal. 2006, 18, 21-46.

52. Setzer, M.C.; Moriarity, D.M.; Lawton, R.O.; Setzer, W.N.; Gentry, G.A.; Haber, W.A. Phytomedicinal potential of tropical cloudforest plants from Monteverde, Costa Rica. Rev. Biol. Trop. 2003, 51, 647-673.

53. Schmidt, J.M.; Noletto, J.A.; Vogler, B.; Setzer, W.N. Abaco bush medicine: Chemical composition of the essential oils of four aromatic medicinal plants from Abaco Island, Bahamas. J. Herbs Spices Med. Plants 2006, 12. [CrossRef]

54. Wilkinson, G.N. Statistical estimations in enzyme kinetics. Biochem. J. 1961, 80. [CrossRef] [PubMed]

55. Maxson, T.; Mitchell, D.A. Targeted treatment for bacterial infections: Prospects for pathogen-specific antibiotics coupled with rapid diagnostics. Tetrahedron 2016, 72, 3609-3624. [CrossRef] 